\title{
Recovery in a letter-by-letter reader: more efficiency at the expense of normal reading strategy
}

\author{
Irene Ablinger ${ }^{1,2}$, Walter Huber' ${ }^{2}$, Kerstin I. Schattka ${ }^{1,2}$, and Ralph Radach \\ ${ }^{1}$ Department of Neuropsychology, RWTH Aachen University Hospital, Aachen, Germany \\ ${ }^{2}$ Clinical and Cognitive Neurosciences, Department of Neurology, RWTH Aachen University Hospital, \\ Aachen, Germany \\ ${ }^{3}$ General and Biological Psychology, University of Wuppertal, Wuppertal, Germany
}

\begin{abstract}
Although changes in reading performance of recovering letter-by-letter readers have been described in some detail, no prior research has provided an in-depth analysis of the underlying adaptive word processing strategies. Our work examined the reading performance of a letter-by-letter reader, $\mathrm{FH}$, over a period of 15 months, using eye movement methodology to delineate the recovery process at two different time points (T1, T2). A central question is whether recovery is characterized either by moving back towards normal word processing or by refinement and possibly automatization of an existing pathological strategy that was developed in response to the impairment. More specifically, we hypothesized that letter-by-letter reading may be executed with at least four different strategies and our work sought to distinguish between these alternatives. During recovery significant improvements in reading performance were achieved. A shift of fixation positions from the far left to the extreme right of target words was combined with many small and very few longer regressive saccades. Apparently, 'letter-by-letter reading' took the form of local clustering, most likely corresponding to the formation of sublexical units of analysis. This pattern was more pronounced at $\mathrm{T} 2$, suggesting that improvements in reading efficiency may come at the expense of making it harder to eventually return to normal reading.
\end{abstract}

Keywords: Letter-by-letter; Pure alexia; Recovery process; Eye movements; Reading strategy.

As a result of occipito-temporal lesions (Cohen et al., 2003) letter-by-letter reading is characterized by an effortful serial word processing, from left to right, leading to a pathological length effect in reading aloud. In fact, single word reading latencies may increase from 500 to $3000 \mathrm{~ms}$ per additional letter (Fiset, Arguin, \& McCabe, 2006; Hanley \& Kay, 1996). In many cases the term letter-by-letter reading is used synonymous with pure alexia or alexia without agraphia (Behrmann, Shomstein, Black, \&
Barton, 2001; Fiset, Arguin, Bub, Humphreys, \& Riddoch, 2005), provided that there are no writing and spelling deficits. Even when additional aphasic impairments are present, the characteristics of letter-by-letter reading can still be recognized (e.g., Ablinger \& Domahs, 2009; Benson, Brown, \& Tomlinson, 1971; Greenwald \& Gonzalez-Rothi, 1998; Nitzerg Lott \& Friedman, 1999; Sage, Hesketh, \& Lambon Ralph, 2005). Independent of whether the underlying deficit is related to a

The present investigation was supported by the German Science Foundation, DFG (project HU 292/9-2). We would like to thank patient FH for participating in our study. We are grateful to Prof. Klaus Willmes for his advice during data analysis, Dr. Michael Mull for providing his expertise in the interpretation of the radiological images and two anonymous reviewers who made extremely helpful suggestions on a previous version of this manuscript.

Address correspondence to Irene Ablinger, Dr.rer.medic.; Dipl.-Log., Section Neuropsychology/Clinical and Cognitive Neurosciences, Department of Neurology, RWTH Aachen University Hospital, Pauwelsstrasse 30, D-52074 Aachen, Germany. (E-mail: iablinger@ukaachen.de).

(C) 2012 Psychology Press, an imprint of the Taylor \& Francis Group, an Informa business 
general visual impairment (Behrmann, Plaut, \& Nelson, 1998; Farah \& Wallace, 1991; Mycroft, Behrmann, \& Kay, 2009; Starrfelt, Habekost, \& Leff, 2009) or more directly affects letter identification and/or orthographic integration of letter units (Hanley \& Kay, 1996; Patterson \& Kay, 1982; Rosazza Appollonio, Isella, \& Shallice, 2007), pure alexia is associated with an early visual orthographic impairment affecting fast parallel processing of letters.

Recent research (Arguin \& Bub, 2005; Fiset et al., $2005,2006)$ confirmed that letter-by-letter readers have difficulties with the discrimination and identification of visually similar letters. Specifically, the characteristic symptom of a letter-by-letter reader, the word length effect, disappeared when words were matched on summed letter confusability. In addition to the contribution of low-level factors (word length, letter confusability), the reading process is also influenced by high-level representations, indicating residual parallel letter processing abilities. Increasing lexical frequency, imageability, or orthographic neighborhood size led to faster responses in letter-by-letter reader (Arguin, Fiset, \& Bub, 2002; Behrmann et al., 2001; Fiset et al., 2006; Johnson \& Rayner, 2007; Rayner \& Johnson, 2005). Similarly, some patients possess implicit reading abilities (referred to as the Saffran effect), i.e., lexical and/or semantic judgments under brief stimulus presentation may be carried out without being able to name the target item (Roberts, Lambon Ralph, \& Woollams, 2010; Lambon Ralph, Hesketh, \& Sage, 2004; Saffran \& Coslett, 1998; Shallice \& Saffran, 1986). Fiset et al. $(2005,2006)$ argued that letterby-letter readers like normal readers try to access words by parallel identification of letter units as a default mechanism (see also Behrmann, Plaut et al., 1998). But due to their letter encoding deficit a distinction of the appropriate letters is impossible and they have to switch to a compensatory serial letter processing strategy. Behrmann, Plaut et al. (1998) suggested that fragmentary input information may be partly compensated by top-down processes. All in all, the reliance of bottom-up and top-down information probably varies from patient to patient depending on the extent to which the bottom-up information is weakened following brain damage (Behrmann, Nelson, \& Sekuler, 1998; Lambon Ralph et al., 2004).

Over the last three decades, the recording and analysis of eye movements has become one of the key methodologies to study information processing in reading (see Radach \& Kennedy, 2004;
Rayner, 1998, for overviews). More recently, this methodology has been applied successfully to gain a better understanding of visuomotor and linguistic mechanisms of pathological reading in both peripheral and central aphasia (e.g., Behrmann et al., 2001; Johnson \& Rayner, 2007; Rayner \& Johnson, 2005; Schattka, Radach, \& Huber, 2010).

Behrmann and colleagues were the first who investigated eye movement characteristics in letterby-letter readers asking them to read sentences aloud. Overall, the two participants in their study exhibited more fixations, longer fixation durations, and a higher number of regressive saccades compared to controls. In addition, there were also clear frequency and imageability effects, both more pronounced for long words. Thus, these results confirmed the importance of both low-level (word length) and high-level (word frequency, imageability) factors for word identification in letterby-letter readers (see also Rayner \& Johnson, 2005). A new angle was recently added to the discussion by Johnson and Rayner (2007), who tested effects of contextual word predictability (topdown) and summed letter confusability (bottomup). An increase of letter confusability led to longer fixation durations and more fixations, while, on the contrary, high word frequency and sentencelevel predictability were related to shorter and fewer fixations. Interestingly, these authors also demonstrated that top-down information was mainly effective for letter positions at the end of the word. Because of the grapheme encoding deficits in their patient GJ, letters at the beginning of a word generally required more time and were fixated more often than those at the end of a word. The impact of contextual constraint as word predictability, frequency, and semantics increased with the number of identified graphemes.

A number of prior studies focused on the rehabilitation of letter-by-letter reading. This work is not directly relevant for the present case, but results are informative as an estimate of potential improvement during the course of recovery, assuming that treatment outcomes tend to be better than spontaneous remission. In general, treatment of letter-by-letter readers yielded significant improvements in reading accuracy and latency, but there was also a residual word length effect pointing towards a continued letter-by-letter reading procedure (Ablinger \& Domahs, 2009; Arguin \& Bub, 1994; Behrmann \& McLeod, 1995; Bohn \& Stadie, 2005; Friedman \& Nitzberg Lott, 2000; Nitzberg Lott \& Friedman, 1999; Lott, Friedman, 
\& Linebaugh, 1994; Gonzalez Rothi \& Moss, 1992; Sage et al., 2005; Seki, Yajaima, \& Sugishita, 1995). Results on treatment are quite similar to the earlier findings reported in a seminal paper by Behrmann, Black, and Bub (1990). These authors monitored the progress of spontaneous recovery in their patient DS, who still demonstrated characteristics of letter-by-letter reading after a period of 12 months. DS showed quite accurate letter identification abilities but had enormous difficulties with parallel letter identification under limited exposure duration and words were read in a sequential letter-by-letter fashion. Furthermore, DS was unable to access orthographic word forms as a whole. Although still differing from controls, in the course of recovery, DS's reaction time in oral reading and lexical decision decreased significantly. However, due to her persistent word length effect, she still demonstrated characteristics of letter-byletter reading.

\section{THE PRESENT STUDY}

Examining the progression of recovery in letterby-letter readers may contribute to a better understanding of the underlying mechanisms affecting the reading process. To our knowledge, there are only two prior studies describing the recovery of letter-by-letter readers over a longer period (Behrmann et al., 1990; Friedman \& Alexander, 1984). Although both studies conclude that their patients have refined their compensatory reading strategy, they do not provide evidence on what this reading strategy precisely looked like.

Consequently, the present work used online eye tracking methodology to assess the underlying reading strategy and its changes during the course of recovery. The recovery of $\mathrm{FH}$, a letter-by-letter reader, was studied in detail over a period of 15 months. Our main goal was to provide a finegrained analysis of changes in his specific reading strategies. To this end, we examined word level fixation patterns in a sequential word reading task, considering the influence of word length, lexical frequency, and concreteness.

One major question that can be addressed with this kind of approach is whether the recovery process is characterized either by change in strategy back to normal word processing or by refinement and possibly automatization of an existing strategy that was developed in response to the impairment. To map out a space of possible answers to this question, we hypothesized that letter-by-letter reading might be executed with at least four different underlying strategies. We reasoned that these strategies may be distinguished on the basis of the sequence of fixation positions, the amplitude and proportion of regressive and progressive saccades and an additional error analyses.

1. According to 'type-writer' strategy, a patient would gradually read through the word in very small, letter-size steps, from left to right. When reaching the word end without identifying the target word meaning, the process will have to start again from the word beginning. As a result, relatively few short regressive amplitudes will occur, whereas longer regressive amplitude from the word end to the word beginning would reflect a startover of the attempted reading process from left to right. This is the pattern of results to expect if patients with pure alexia were literally letter-by-letter readers. Empirical support for this hypothesis comes from work by Rayner and Johnson (2005) who forced normal participants to read within a gaze contingent one letter window and observed a performance pattern that appeared very similar to results obtained with an LBL reader. They conclude that 'at the level of initial encoding' letters are indeed encoded serially by letter-by-letter readers (p. 533). As mentioned earlier, Fiset et al. (2006) have attributed letter-by-letter dyslexia to a breakdown on parallel letter processing. Based on a series of thoughtful experiments they argue that letter-by-letter readers compensate this severe deficit by switching to purely sequential letter processing, thus avoiding the massive letter confusion present in parallel processing. If this is indeed the case in our patient $\mathrm{FH}$, the resulting oculomotor pattern should correspond to the one we have outlined earlier. Moreover, if he develops a tendency towards compensatory serial letter processing, data collected later during the process of recovery should be more similar to the type-writer account.

2. When using a 'local clustering' strategy, processing would be focused on the assembly of letter clusters, forming sub-word chunks as preliminary units of analysis. Once formed, these units are maintained and used in the gradual build up of a target word representation. This strategy would correspond to observing a much more gradual move across the word, in a 
more or less zigzag-like pattern, perhaps even hovering over certain regions within a word when local processing is particularly difficult. Consequently, there should be a much larger number of very short regressive eye movements, and these regressions should be more equally distributed across words. This strategy could be attributed to more or less successful attempts to engage in concurrent letter processing on a local level, most likely aided by top-down processing as would be evident in semantic and lexical processing effects (e.g., Behrmann, Plaut et al., 1998). This suggested strategy can also be related to recent work by Pflugshaupt et al. (2011), who compared performance in reading words with transposed letters in normal vs. letter-by-letter readers. Their results point to word form processing (letter order as opposed to letter similarity) as a major locus of deficits in pure alexia. In the absence of holistic word processing (see later), any substantial attempts towards local parallel processing of sublexical units would have their oculomotor expression in terms of the suggested local clustering pattern.

3. On the basis of a more 'holistic' strategy, the word reading process should still start at the left and initially proceed in small steps through the word. However, towards the end of the process, there should be a transition towards more and more fixations being localized near the word center as found in normal readers. It is also likely that the slow serial decoding process does not have to go all the way to the word end before enough letter-level information is acquired, leading to a leftward shift in the spatial distribution of saccade landing positions. Another variant of holistic processing could manifest itself in initial saccades further into the target word, reflecting attempts to process a larger substring of letters in parallel (see Schattka et al., 2010, for comparisons between more lexical vs. more sequential reading strategies in patients with central dyslexia). Importantly, evidence for these and any other deviations from a strictly serial interword saccade progression observed at T2 would suggest a return to a more lexical word processing strategy over the course of recovery.

4. The use of a 'lexical guessing strategy' should be characterized by frequent termination of attempted word processing based on incomplete evidence, leading to many visual guessing errors. In terms of eye movement patterns, this suboptimal strategy could include elements of all three strategies of processing discussed earlier. Typically, however, there should be a premature termination of word viewing at more or less random positions across target words. This hypothesis is related to prior reports on error patterns observed in letter-by-letter readers. As an example, patient RS, described by Friedmann and Nitzberg Lott (2000), produced a substantial number of guesses on the basis of recognizing the first letter of a word. Seen from an oculomotor perspective, this type of strategy would be in harmony with an increased number of fixations and perhaps longer fixation durations at the beginning of words in comparison to word center and word end, as observed by Johnson and Rayner (2007).

\section{METHODS}

\section{Case description}

FH is a native speaker of German and previously worked as an engineer. At the age of 46 he suffered from a dissection of the left internal carotid artery (ICA) followed by multiple ischemic infarcts in the territory of the left middle and posterior cerebral artery. As a consequence he initially suffered from global aphasia with alexia and agraphia and right-sided hemianopia. Six months post onset MRI scans showed an extended cortical and subcortical lesion of the temporal lobe extending into the inferior parietal lobe as well as small lesions of the anterior lentiform nucleus and of the occipital cortex (BA 19). MRI angiography revealed weak spontaneous recanalization of the occluded left ICA. Furthermore, a direct origin of the left posterior cerebral artery from ICA was found as a normal variant explaining the occurrence of lesions in both MCA and PCA territory. The visual word form area (VWFA) in mid fusiform gyrus was laterally damaged and the adjacent white matter was largely destroyed (see Figure 1). Thus, the damage also affected the vicinity of the temporo-parietal portion of the perisylvian language zone while the inferior frontal portion remained undamaged.

FH was admitted to the Aachen aphasia ward three times; 3, 15, and 30 months post onset, where he received a 7-week language therapy each time. Three months post onset he presented a severe transcortical sensory aphasia which was 


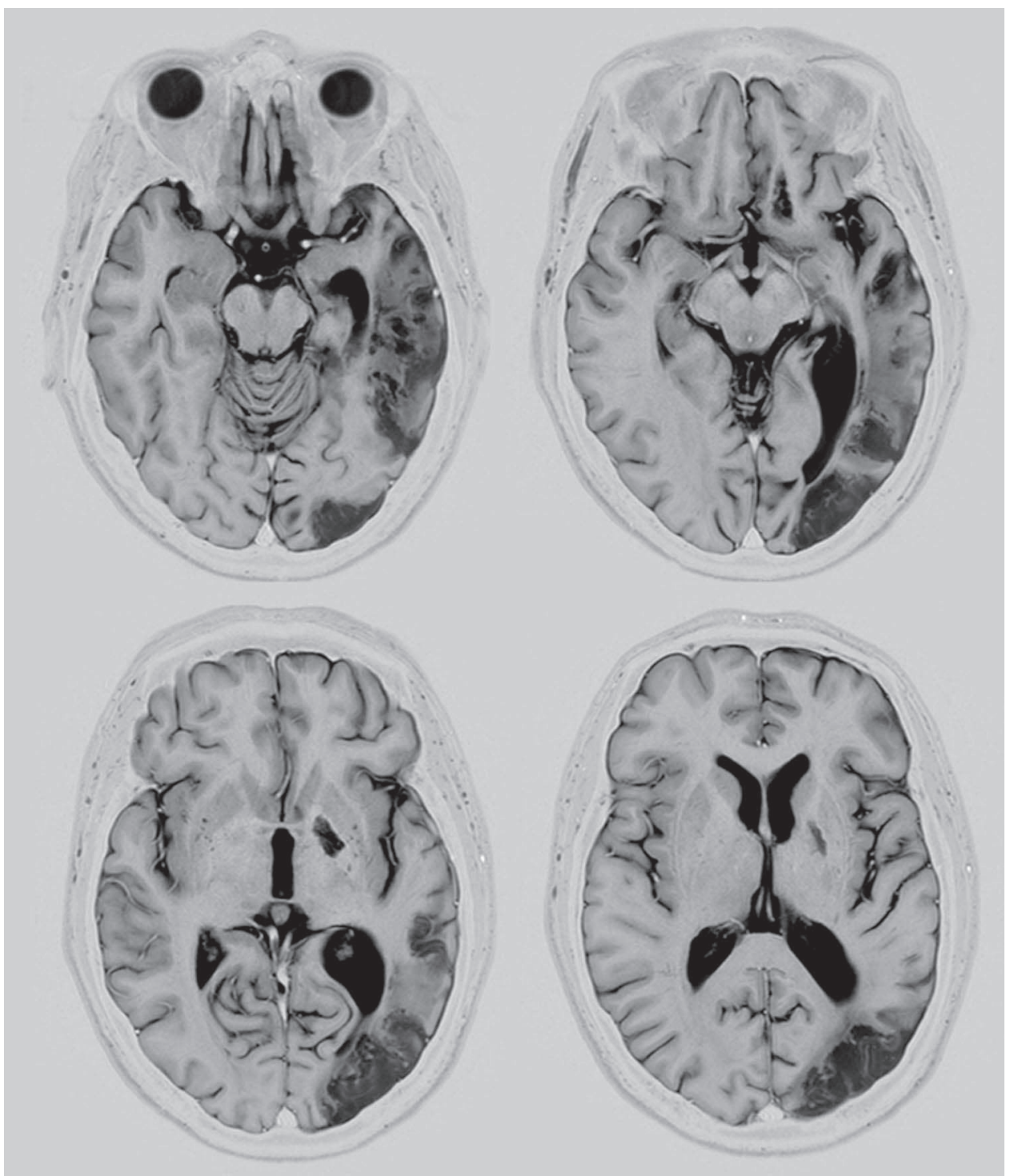

Figure 1. MRI scans of FH showing large left temporal lesion affecting lateral part of VWFA and adjacent cortical and subcortical areas.

characterized by outstandingly good repetition in contrast to severe impairment in all other expressive and receptive modalities. Speech output was fluent with many paraphasias, empty stereotypical phrases, severe word finding difficulties, and incomplete sentences. Reading aloud of words was impossible, he could only produce a few letter names or corresponding single phonemes which led to lexical guessing or breaking off. Even phonemic and/or alphabetic identification of individual letters was inaccurate or impossible in half of the observations and took several seconds.

A systematic exploration of FH's reading abilities was only possible when a chronic stage was reached and the initially severe impairment was changed into an overall moderate one. The present study provides a systematic comparison of FH's reading performance at 15 and 30 months post onset (T1, T2).

\section{Examination of nonverbal function}

At the time of the first testing (T1), the Edinburgh Inventory (Oldfield, 1971) showed complete righthandedness (L.Q.100, R.10). No signs of ideomotor apraxia (De Renzi, Motti, \& Nichelli, 1980) or buccofacial apraxia (Poeck, 1997) were 
detected. Moreover, no speech apraxia was present. The visual field was assessed with an automated Humphrey perimeter (manufacturer's $30-2$ protocol) and Goldmann perimetry (III/4). Results showed an incomplete right-sided hemianopia, mainly restricted to the right lower quadrant. This finding was found unchanged during re-assessment at T2. The right periphery was not affected up to a distance of $8^{\circ}$ (corresponding to 24 letters in our display), completely sparing the perceptual 8-10 letter span for letter recognition in reading (e.g., Rayner, Well, Pollatsek, \& Bertera, 1982; Underwood \& McConkie, 1985).

Table 1 provides an overview of neuropsychological testing results with respect to nonverbal intelligence, nonverbal memory, and learning and attention. In comparison to normal population, FH's performance was either in the lower average range or slightly below average. Basic occulomotor functions were examined at $\mathrm{T} 1$ in a visually guided saccade task with LEDs at a distance of 20 degrees visual angle (Hund \& Huber, 1991). His values for left/right latencies (target left: mean $=159 \mathrm{~ms} / S D=65$; controls: 157/50; target right: 151/33; controls: $154 / 33$ ) fell into the normal range. This was also true for amplitudes of leftward saccades (19.3 degrees/1.1; controls: 19.1/1.4) while his rightward saccades were somewhat shorter (16.3/2.4; controls 19.5/1.8; $t$-test, $p=.039$ ). This was most likely due to the parieto-occipital portion of FH's lesion which slightly affected programming long visually guided saccades to the contralesional side (Hund \& Huber, 1991; Schuett, Kentridge, Zihl, \& Heywood, 2009; Zihl, 1995a). In sum, the perimetric and the oculomotor findings demonstrate that neither visual spans nor short saccades as required for word reading were affected in FH. Thus, his reading difficulties did not fulfill the characteristics of hemianopic alexia (Leff et al., 2000; McDonald, Spitsyna, Shillcock, Wise, \& Leff, 2006; Pflugshaupt et al., 2009; Zihl, 1995b).

Due to time constraints at $\mathrm{T} 1$, we were not able to look for a potential general visual impairment in more detail. However at T2, a number of subtests of the Birmingham Object Recognition Battery (Riddoch \& Humphreys, 1993) could be administered. FH's scores placed him within normal range in tasks addressing length matching $(27 / 30$, normal cut off: 24$)$, size matching with circles $(26 / 30,23)$, orientation matching with parallel lines $(28 / 30,20)$, and gap position matching $(37 / 40,27)$.
TABLE 1

Neuropsychological tests results at T1

\begin{tabular}{|c|c|}
\hline Task & Results \\
\hline \multicolumn{2}{|l|}{ Nonverbal Intelligence } \\
\hline Abstract logical thinking (LPS3) ${ }^{1}$ & $\mathrm{~T}=45$ \\
\hline Spatial rotation (LPS7) ${ }^{1}$ & $\mathrm{~T}=30$ \\
\hline Figure-ground discrimination (LPS10) ${ }^{1}$ & $\mathrm{~T}=40$ \\
\hline \multicolumn{2}{|l|}{ Nonverbal Memory and Learning } \\
\hline Visuospatial memory span ${ }^{2}$ & $\mathrm{~T}=47$ \\
\hline Nonverbal Learning (NVLT) ${ }^{3}$ & $\mathrm{~T}=41$ \\
\hline \multicolumn{2}{|l|}{ Attention $^{4}$} \\
\hline Alertness without warning & $\mathrm{T}=46$ \\
\hline Alertness with warning & $\mathrm{T}=42$ \\
\hline Selective attention (GO/NO GO Test), speed & $\mathrm{T}=40$ \\
\hline
\end{tabular}

Standardized Scores derived from normal population: T-value (T), normal range: 40-60;

${ }^{1}$ Leistungsprüfsystem (LPS) (Horn, 1983);

${ }^{2}$ Corsi Block Tapping Test (Smirni, Villardita \& Zappala, 1983); ${ }^{3}$ Nonverbaler Lerntest (Sturm \& Willmes, 1999): Nonverbal learning test; the patient is confronted with meaningless figures; 8 of the items recur in the test; on each item the patient has to decide whether it is known to him or not. Correct positive as well as false positive reactions determine the learning gradient.;

${ }^{4}$ Test for attentional performance (Zimmermann \& Fimm, 1997)

\section{Examination of language functions}

The course of aphasia was assessed by means of the Aachen Aphasia Test (AAT; Huber, Poeck, Weniger, \& Willmes, 1983; Huber, Poeck, Willmes, 1985). As shown in Table 2, outstandingly good repetition performance remained characteristic throughout recovery, even though all other modalities improved significantly between 3 and 15 months post onset. Spontaneous language also improved with respect to overall communicative ability and language systematic structures. At T1 (15 months post onset) $\mathrm{FH}$ was able to convey his ideas despite linguistic impairments. Syntax was long and complex with inaccurate or missing function words and at times even incomplete or paragrammatic (i.e., sentence parts were doubled or blended). Phonemic paraphasias were rare. However, there were still many semantic paraphasias and severe word finding difficulties. These symptoms of spontaneous language remained basically unchanged over the next 15 months (T2). Among the language modalities only the performance of confrontation naming showed further significant improvement.

At T1 writing was executed with many hesitations and the production of phonemic paragraphias. Oral reading was very effortful, with an 
TABLE 2

Aachen Aphasia Test (AAT) performance

\begin{tabular}{|c|c|c|c|c|c|c|c|}
\hline & & \multicolumn{2}{|c|}{3 months p.o. } & \multicolumn{2}{|c|}{$\begin{array}{c}15 \text { months p.o. } \\
T 1\end{array}$} & \multicolumn{2}{|c|}{$\begin{array}{c}30 \text { months p.o. } \\
T 2\end{array}$} \\
\hline Spontanous speech & Range & \multicolumn{2}{|c|}{$R S$} & \multicolumn{2}{|c|}{$R S$} & \multicolumn{2}{|c|}{$R S$} \\
\hline Communicative ability & $0-5$ & \multicolumn{2}{|c|}{2} & \multicolumn{2}{|c|}{3} & \multicolumn{2}{|c|}{3} \\
\hline Articulation \& prosody & $0-5$ & \multicolumn{2}{|c|}{5} & \multicolumn{2}{|c|}{5} & \multicolumn{2}{|c|}{5} \\
\hline Automatic speech & $0-5$ & \multicolumn{2}{|c|}{3} & \multicolumn{2}{|c|}{3} & \multicolumn{2}{|c|}{3} \\
\hline Semantic structure & $0-5$ & \multicolumn{2}{|c|}{2} & \multicolumn{2}{|c|}{3} & \multicolumn{2}{|c|}{3} \\
\hline Phonemic structure & $0-5$ & \multicolumn{2}{|c|}{3} & \multicolumn{2}{|c|}{4} & \multicolumn{2}{|c|}{4} \\
\hline Syntactic structure & $0-5$ & \multicolumn{2}{|c|}{2} & \multicolumn{2}{|c|}{3} & \multicolumn{2}{|c|}{3} \\
\hline Subtests & Range & $R S$ & $P R$ & $R S$ & $P R$ & $R S$ & $P R$ \\
\hline Token Test & $50-0^{1}$ & 39 & 30 & 24 & $56^{*}$ & 20 & 65 \\
\hline Repetition & $0-150$ & 138 & 83 & 143 & 89 & 139 & 84 \\
\hline Written language & $0-90$ & 12 & 23 & 67 & $69^{*}$ & 75 & 80 \\
\hline Confrontation naming & $0-120$ & 35 & 28 & 75 & $48^{*}$ & 93 & $68^{*}$ \\
\hline Comprehension & $0-120$ & 54 & 23 & 85 & $59^{*}$ & 82 & 55 \\
\hline
\end{tabular}

apparent serial reading strategy. More specifically, attempts to read a word were characterized by sounding out individual letters or combinations of letters, i.e., producing corresponding phonemes but hardly syllables. Multiple letter graphemes were recognized in most cases. In contrast to his post acute performance 3 months post onset, sounding out words now resulted in most instances in a fluently pronounced correct response. Reading latencies were still very much increased with long pauses between sounding out and producing the target word.

\section{Testing of specific letter and word processing abilities}

FH's performance with respect to different aspects of word processing at $\mathrm{T} 1$ is summarized in Table 3. Fifteen months post onset FH was able to identify $88 \%$ of capital letters without errors but performance was characterized by an inflated mean naming latency (3209 ms). He had no difficulties to discriminate written pairs of real words or neologisms as same or different (LeMo, De Bleser, Cholewa, Stadie, \& Tabatabaie, 2004). Lexical decision, i.e., classifying stimuli as words, pseudowords and nonwords (AAT supplement reading; Huber et al., 1993), was only slightly impaired on both, auditory and visual presentation. In a visual pseudohomophone decision task (LeMo, De Bleser et al., 2004), FH had clearly more problems, but performed above chance, when he had to reject pseudowords that were pronounced like real words as non existing written words of German. Synonym judgments with semantic distractors (LeMo) revealed an impaired performance (just above chance level) for visual presentation but only slight impairment for auditory presentation. To quantify the word length effect typical for letter-by-letter reading, $\mathrm{FH}$ was asked to read aloud real words that varied in length (10 short words $=4-5$ letters, 10 long words $=8-9$ letters). Reading latency increased dramatically, with mean latency amounting to $4037 \mathrm{~ms}$ for short and $7772 \mathrm{~ms}$ for long words (MannWhitney $U$-test, $p=.003$ ). Reading performance was characterized by sounding out letters and long hesitations before naming the target word. Accuracy was correct in $100 \%$ of the 10 stimuli each. In addition the impact of orthographic regularity was assessed (LeMo, De Bleser et al., 2004). $\mathrm{FH}$ was again quite accurate for regular words and showed only few regularization errors on irregular words. Both, the low incidence of regularization errors and of phonemic paraphasias in word reading excluded the differential diagnosis of central surface dyslexia.

At T2 we re-examined basic functions of word processing (see Table 4). Word discrimination was now flawless and the performance on lexical decision remained unchanged. With a limited presentation time of $250 \mathrm{~ms}$, FH still performed above chance with $74 \%$ correct responses. The majorities of errors consisted in failure to reject pseudowords, where his performance was still at chance level $(26 / 40,65 \%$ correct; $95 \%$ confidence 
TABLE 3

Performance in letter and word processing tasks at T1, 15 months post onset

\begin{tabular}{|c|c|c|c|}
\hline Task & Accuracy & Accuracy $(\%)$ & Mean latenccy \\
\hline Letter identification & $46 / 52$ & 88 & $3209 \mathrm{~ms}$ \\
\hline \multicolumn{4}{|l|}{ Visual discrimination $(\mathrm{LeMo})^{1}$} \\
\hline word pairs & $65 / 68$ & 96 & \\
\hline neologism pairs & $71 / 72$ & 99 & \\
\hline \multicolumn{4}{|l|}{ Lexical decision $^{2}$} \\
\hline auditory & $86 / 90$ & 96 & \\
\hline visual & $76 / 90$ & 84 & \\
\hline Visual pseudohomophone decision (LeMo) & $51 / 80$ & 64 & \\
\hline \multicolumn{4}{|l|}{ Synonym judgement (LeMo) } \\
\hline auditory (2-choice) & $33 / 38$ & 87 & \\
\hline visual (4-choice) & $9 / 19$ & 47 & \\
\hline \multicolumn{4}{|l|}{ Word reading } \\
\hline 5 letters & $10 / 10$ & 100 & $4037 \mathrm{~ms}$ \\
\hline 8-9 letters & $10 / 10$ & 100 & $7772 \mathrm{~ms}$ \\
\hline \multicolumn{4}{|l|}{ Word reading (LeMo) } \\
\hline regular & $19 / 20$ & 95 & \\
\hline irregular & $35 / 40$ & 88 & \\
\hline
\end{tabular}

${ }^{1}$ Lexikon modellorientierte Einzelfalldiagnostik bei Aphasie, Dyslexie und Dysgraphie (De Bleser, Cholewa, Stadie \& Tabatabaie, 2004)

${ }^{2}$ AAT supplement reading (Huber, Klingenberg, Poeck, \& Willmes, 1993)

TABLE 4

Performance letter and word processing tasks at T2, 30 months post onset

\begin{tabular}{|c|c|c|}
\hline \multirow[b]{2}{*}{ Task } & \multicolumn{2}{|c|}{$T 2$} \\
\hline & Accuracy & Accuracy $\%$ \\
\hline \multicolumn{3}{|l|}{ Visual dscrimination (LeMo) ${ }^{1}$} \\
\hline word pairs & $73 / 73$ & 100 \\
\hline neolgismen pairs & $70 / 70$ & 100 \\
\hline \multicolumn{3}{|l|}{ Lexical decision (LeMo) } \\
\hline auditory & $77 / 80$ & 96 \\
\hline visual & $70 / 80$ & 88 \\
\hline visual, 250ms time limit & $59 / 80$ & 74 \\
\hline \multicolumn{3}{|l|}{ Letter perception (PALPA) ${ }^{2}$} \\
\hline letter orientation test & $35 / 36$ & 97 \\
\hline allograph matching & $52 / 52$ & 100 \\
\hline allograph matching of letter strings ${ }^{3}$ & $29 / 30$ & 97 \\
\hline \multicolumn{3}{|l|}{ Letter identification } \\
\hline letter in letter string ${ }^{4}$ & $18 / 19$ & 95 \\
\hline letter naming & $46 / 52$ & 88 \\
\hline \multicolumn{3}{|l|}{ First and last letter identification } \\
\hline neologismen short: exposure duration of $300 \mathrm{~ms}$ & $40 / 49$ & 82 \\
\hline words short: exposure duration of $300 \mathrm{~ms}$ & $44 / 47$ & 94 \\
\hline words long: exposure duration of $300 \mathrm{~ms}$ & $5 / 20$ & 25 \\
\hline $500 \mathrm{~ms}$ & $10 / 20$ & 50 \\
\hline $800 \mathrm{~ms}$ & $19 / 20$ & 95 \\
\hline
\end{tabular}

${ }^{1}$ Lexikon modellorientierte Einzelfalldiagnostik bei Aphasie, Dyslexie und Dysgraphie (De Bleser, Cholewa, Stadie \& Tabatabaie, 2004)

${ }^{2}$ Psycholinguistic Assessments of Language Processing in Aphasia (Kay, Lesser, \& Coltheart, 1992)

3 judgement whether letter strings are similar or not achd ACHD

${ }^{4}$ judgement whether shortly presented letter $(300 \mathrm{~ms})$ is part of a string of 5 letters 
interval: $49-79 \%)$. With respect to letter processing he showed no deficits in visual spatial and allographic tasks. Likewise letter identification was unimpaired in a matching task, when briefly presented $(300 \mathrm{~ms})$ target letters had to be identified in temporally unlimited strings of 5 letters. In untimed single letter naming FH exhibited prolonged naming latencies with a mean of $1600 \mathrm{~ms}$ per letter and an error rate comparable to T1. Similar naming performance was achieved for the first and last letter in short neologisms and real words with limited exposure duration of $300 \mathrm{~ms}$. However, when the stimuli consisted of long words the performance was dropped to $25 \%$. Performance improved when the exposure duration was increased up to $800 \mathrm{~ms}$. Apparently, this reflects the fact that FH was not able to recognize long words with brief presentation in a holistic fashion.

\section{Control group}

In the experimental eye movement study FH's reading performance was compared with an age matched control group $(n=8$; mean $=56$ years; range $=40$ and 68 years). All participants were right-handed native German speakers, showed normal or corrected vision and had no history of neurological or psychiatric disabilities.

\section{Stimuli}

In constructing the experimental stimuli, 32 healthy subjects who did not participate in the present experiment were asked to judge 657 potential targets as concrete or abstract. From this pool, 160 five- to eight-letter words with the highest inter-rater reliability were selected as targets to examine in an orthogonal design the influence of word length, lexical frequency and concreteness. To this end, target words were equally divided into high and low frequency words (high frequency: mean $=82.2$ per million; range $=29-193$; $S D=21.95$; low frequency: mean $=0.6$ per million; range $=0.33-0.83 ; S D=0.02$; CELEX database, German version, 1995), and concrete and abstract words, respectively.

\section{Procedure and apparatus}

To examine in detail FH's reading performance, he was asked to read aloud the full sample of target words at both testing points $\mathrm{T} 1$ and $\mathrm{T} 2$
(15 and 30 months post onset), while eye movements and articulation were recorded simultaneously. Target words were presented on the computer screen arranged in lines similar to normal sentence reading. This alignment preserved the normal spatial configuration found in text reading so that visual processing demands were close to a natural reading situation. Importantly, the task of reading a sequence of well-controlled nouns avoids higher order post-lexical processing on the sentence and text level that often overwhelms patients with severe reading disabilities. We have validated this task with two samples of control participants independently from the present study, showing that spatial and temporal eye movement measures reflect processing demands induced by word length, frequency and concreteness in a way very similar to normal reading (see Inhoff \& Radach, 1998, for a detailed discussion of eye movement research design and measures). This methodology was used successfully in our laboratory to examine patients suffering from mild to moderate central dyslexia in the context of aphasia, again showing sensitivity to visual and cognitive processing demands (Schattka et al., 2010).

Eye movements were recorded using an SR EyeLink II video-based head-mounted eye tracking system. The registration is based on infrared-light reflection from pupil and cornea at a sampling rate of $250 \mathrm{~Hz}$. Viewing was binocular but eye movements were recorded from the right eye only. Head position was recorded by an additional head mounted camera and small movements were compensated on-line. After adjusting the headband, the participant's eye position was calibrated using 3 black dots placed equidistantly on a horizontal target line. Targets were presented individually in fixed order and subjects were asked to fixate each dot, which was automatically controlled by the eye tracking system. Calibration was initiated and carried through by the participant pressing the space bar on a gamepad. Calibration was immediately followed by a validation routine that determined the stability and accuracy of the initial measurement.

The target words were displayed in black on a grey background using a 21-inch CRT monitor running at a resolution of $1024 \times 768$. Text was presented in non-proportional 15-point Courier font corresponding to 12 pixels per letter horizontally. At a viewing distance of $54 \mathrm{~cm}$, each character subtended approximately $0.5^{\circ}$ of visual angle. Blanks before words had the width of a character. After the first calibration, the reading task was demonstrated using one line of eight practice items. Participants 
were asked to fixate a cross at the left end of the line before the eight written words were shown simultaneously. This was the signal to start reading aloud all eight words in a sequence. When finished, the participant pressed a key on the gamepad which caused the stimuli to disappear and to present a new fixation cross. During each session, verbal expressions were digitally recorded on a computer (Adobe Audition, 1.5) for subsequent linguistic analysis.

\section{Data selection and analysis}

A target word was included in the data analysis when a fixation fell on at least one of its constituent letters or on the blank space preceding it. Data were organized in terms of pairs of incoming saccades and following fixation durations. Observations containing blinks or fixation durations shorter than $70 \mathrm{~ms}$ or longer than $2000 \mathrm{~ms}$, and those outside of $3 S D$ s of the mean were excluded from analyses. In addition to these standard procedures (Inhoff \& Radach, 1998), we also discarded observations with just one fixation per gaze to eliminate cases where eyes have briefly slipped over word boundaries. Overall $7.4 \%$ of the data had to be excluded. The first and last word on the line served as fillers and were not considered in any data analyses.

Letter-by-letter reading is characterized by an extremely inflated number of fixations and viewing time per word. Thus the usual focus on initial fixation duration and gaze duration (summed duration of all fixations before leaving the word) as core indicators of word processing would not have been adequate. Instead, the current study used total reading time (the summed duration of all fixations within the target word including later re-reading), total number of fixations and to some extent mean fixation durations to characterize the reading process of FH (see Inhoff \& Radach, 1998, for a detailed discussion of eye movement measures). This strategy of data analysis is in line with earlier work by Rayner and Johnson (2005) and Johnson and Rayner (2007).

Reading errors were classified into three categories, semantic errors (with semantic relation to the target item), lexical errors (with visual similarity to the target) and neologistic responses. All statistical analyses were computed using SPSS. FH's temporal and spatial eye movement parameters were contrasted to those of the control group with the modified $t$-test by Crawford and Howell (1998). The impact of linguistic parameters was examined using the non-parametric Mann-Whitney $U$-test, performance at different testing points was assessed with the non-parametric Wilcoxon signed-rank test. All statistical analyses are based on one-sided testing.

\section{RESULTS}

In the following section we first report results related to overt reading behaviour. We then examine eye movements in terms of word fixation patterns, focusing on effects of word length, frequency and concreteness. Finally, a fine-grained analysis of fixation positions and sequences tries to determine strategies of word processing in detail.

\section{Overt reading accuracy}

During recovery between 15 and 30 months post onset, FH substantially changed his overt reading behaviour. Analyses of his verbal output indicate that during the initial testing at $\mathrm{T} 1$ he almost exclusively used an overt sequential reading strategy $(149 / 160$ items), which was characterized by sounding out individual letters. This strategy was observed significantly less often at T2 $(15 / 160$ items; McNemar test, $p<.001)$, where $\mathrm{FH}$ produced in most instances correct responses after an extended latency. Accuracy of reading was already high at T1 $(140 / 160)$ and increased even more at T2 (151/160; McNemar test, $p=.013)$. Looking at reading errors, the proportion of neologistic productions (T1: 15/20; T2: 6/9) and lexical errors with visual similarity to the target (T1: $5 / 20$; T2: 3/9) remained relatively stable.

\section{Effects of word properties on viewing times}

Overall, FH's oculomotor behaviour was characterized by very short saccades and inflated fixation durations (see Table 5). Mean fixation durations were substantially longer than those produced by participants in the control group (mean $293 \mathrm{~ms}$ as opposed to $419 \mathrm{~ms}$ for FH at T2). There was no significant difference between testing points (T1 vs. T2: Wilcoxon, $Z=-1.234 ; p=.109$ ).

The overall efficiency of reading in terms of time spent viewing target words improved markedly (see Table 6). Total reading time per word decreased from $9041 \mathrm{~ms}$ at $\mathrm{T} 1$ to $5161 \mathrm{~ms}$ at T2 (Wilcoxon, $Z=-7.556 ; p<.001)$. Accordingly, the total number of fixations was also significantly reduced from an average of 22.2 at T1 to an average of 12.4 fixations at T2 (Wilcoxon, $Z=-7.791 ; p<.001$ ). Still, these values are way beyond anything found 
TABLE 5

Mean fixation duration and Saccade amplitudes at T1 and T2 (standard deviations are given in parenthesis)

\begin{tabular}{lccc}
\hline & Mean fixation duration & Progressive saccade amplitude & Regressive saccade amplitude \\
\hline T1 & $407(65)$ & $1.7(0.4)$ & $2.0(0.7)$ \\
T2 & $419(76)$ & $1.5(0.4)$ & $1.5(0.7)$ \\
controls & $293(103.0)$ & $4.9(1.7)$ & $2.7(2.6)$ \\
\hline
\end{tabular}

TABLE 6

Total reading time (in $\mathrm{ms}$ ) and number of fixations per word as a function of word length (standard deviations are given in parenthesis)

\begin{tabular}{|c|c|c|c|c|c|c|}
\hline \multirow[b]{2}{*}{ Word length } & \multicolumn{3}{|c|}{ Total reading time } & \multicolumn{3}{|c|}{ Total number of fixations } \\
\hline & $T 1$ & $T 2$ & controls & $T 1$ & $T 2$ & controls \\
\hline 5 letters & 6973 (4395) & 4406 (2944) & $513(273)$ & $16.8(9.2)$ & $10.6(7.0)$ & $1.8(1.0)$ \\
\hline 6 letters & 7565 (3091) & 4894 (2606) & $513(200)$ & $18.2(7.7)$ & $12.2(5.6)$ & $1.9(0.8)$ \\
\hline 7 letters & $10013(5502)$ & $5537(2170)$ & 571 (223) & $24.7(12.5)$ & $13.1(5.2)$ & $2.1(1.0)$ \\
\hline 8 letters & $11680(5543)$ & $5808(2331)$ & $618(261)$ & $29.2(13.2)$ & $13.7(5.8)$ & $2.4(1.0)$ \\
\hline overall & $9041(5058)$ & $5161(2564)$ & $555(245)$ & $22.2(11.9)$ & $12.4(6.0)$ & $2.0(1.0)$ \\
\hline
\end{tabular}

in normal readers of the age-matched control group making on the average only 2.0 fixations per word.

\section{Word length effect}

Despite overall improvement of reading performance, FH showed a pronounced word length effect at both testing points (see Table 6). Total reading time ranged from a mean of $6973 \mathrm{~ms}$ for short 5-letter words to $11680 \mathrm{~ms}$ for long 8-letter words in the first examination (T1), and from $4406 \mathrm{~ms}$ to $5808 \mathrm{~ms}$ at T2. For comparison, the normal skilled readers of the control group needed on the average $513 \mathrm{~ms}$ for short and $618 \mathrm{~ms}$ for long words.

To more directly compare the extent of the word length effect, we computed the increase in total viewing time per word for each additional letter increment. This increase per letter amounted to a staggering $1657 \mathrm{~ms}$ at T1, as opposed to $485 \mathrm{~ms}$ at T2. In comparison, for control participants each letter increment required an increase of $37 \mathrm{~ms}$. The incremental effect of word length was strictly linear, with over $96 \%$ of the variance accounted for in linear regression analysis performed on mean viewing durations $\left(\mathrm{T} 1: R^{2}=.96, \mathrm{~T} 2: R^{2}=.98\right)$.

\section{Semantic and lexical frequency effects}

At all three testing points $\mathrm{FH}$ spent significantly less time reading concrete words than abstract words (see Table 7; T1: $p<.001 ;$ T2: $p<.001$, MannWhitney $U$-test). Likewise, the total number of fixations was significantly lower on concrete than on abstract words (Table 7; T1: $p<.001 ; \mathrm{T} 2: p=.008$; Mann-Whitney $U$-test). A significant concreteness effect was also found in the control group for total reading time (see Table 7; $F=17.89, p<.004$; ANOVA) but not for total number of fixations.

While the concreteness of target words showed a strong effect, the influence of lexical frequency was somewhat smaller and not always significant. Total viewing time spent on high frequency words was significantly shorter than on low frequency words at T1 (Mann-Whitney $U$-test, $p=.001$ ), while no difference was found at T2. Similarly, only at $\mathrm{T} 1$ total number of fixations on high frequency words was significantly lower than on low frequency words (Mann-Whitney $U$-test, $p=.004$ ). The control group exhibited a clear word frequency effect, both for total reading time (see Table 7; $F=9.62, p<.017$; ANOVA) and total number of fixations $(F=5.88, p=.046$; ANOVA).

\section{Dynamics of spatially distributed processing: a test of processing strategies}

As discussed in the introduction, we hypothesized about possible strategies that FH could utilize to accomplish word recognition despite his severe impairment. These options include a typewriterstrategy, a local clustering approach, holistic 
TABLE 7

Total reading time (in ms) and number of fixations per word as a function of concreteness and word frequency (standard deviations are given in parenthesis)

\begin{tabular}{|c|c|c|c|c|c|c|}
\hline & \multicolumn{3}{|c|}{ Total reading time } & \multicolumn{3}{|c|}{ Total number of fixations } \\
\hline & $T 1$ & $T 2$ & Controls & $T 1$ & $T 2$ & Controls \\
\hline Concrete & 7417 (4186) & $4482(2115)$ & $539(237)$ & $18.8(10.0)$ & $11.3(5.5)$ & $2.0(1.0)$ \\
\hline Abstract & $10686(5350)$ & $5841(2798)$ & $570(251)$ & $25.5(12.7)$ & $13.5(6.3)$ & $2.1(1.0)$ \\
\hline High frequency & 7662 (4086) & $5185(2628)$ & $516(197)$ & $19.2(9.3)$ & $12.8(6.6)$ & $2.0(0.8)$ \\
\hline Low frequency & $10403(5558)$ & $5138(2516)$ & $593(279)$ & $25.1(13.4)$ & $12.1(5.4)$ & $2.1(1.0)$ \\
\hline
\end{tabular}

attempts at word processing and a lexical guessing strategy. To distinguish between these alternatives, we examined the spatial distribution of fixation positions over time. To this end we divided the total number of fixations per target word in five equal bins and determined the respective distributions of saccade landing positions separately for each word length.

Figure 2 presents key aspects of these data. The upper panels use the example of 8-letter words to compare the distributions of saccade landing positions at T1 and T2, revealing a striking result. FH's saccade landing site distributions initially peak on the word beginning and then, as processing continues, gradually shift all the way to the very end of the word. Moreover, it is quite clear that this pattern is more pronounced at T2, where the individual peaks are almost equidistantly distributed over the entire spatial extent of the target words. The distance between the mean positions for the first and last 20\% fixations is 3.53 letters at T1 and 5.45 letters at $\mathrm{T} 2$ with an average of 0.88 letters rightward shift per $20 \%$ fixations at T1 as opposed to 1.37 letters at $\mathrm{T} 2$.

The lower panels of Figure 2 generalizes these findings to all word lengths, presenting mean landing positions over the time course of word processing for T1 (left) and T2 (right). The strict linearity suggested by these figures was quantified using linear regression analyses on mean saccade landing positions per quintile, which accounted for more than $95 \%$ of the variance in all word length at both $\mathrm{T} 1$ and T2. Slopes of these regressions ranged from 0.52 for 5 -letter words to 1.10 for 8-letter words and were virtually identical for high vs. low frequency and more concrete vs. less concrete words, indicating that these cognitive variables did not affect the pattern of gradual left to right word scanning. It should be noted that these findings are in sharp contrast to results found in normal readers (e.g.,
McConkie, Kerr, Reddix, \& Zola, 1988; Radach, Heller, \& Inhoff, 2004), where saccade landing positions tend to converge towards the word center, reflecting the so-called preferred viewing position (Rayner, 1979; see Schattka et al., 2010, for similar findings on pathologically lexical as opposed to segmental readers in conditions of central dyslexia).

An interesting aspect of the data presented in Figure 2 concerns the variability of landing positions. With the exception of the first $20 \%$ fixation interval (including relatively uniform initial fixations), there is very little difference in standard deviations of saccade landing positions. Summing over all word lengths, the respective standard deviations for the last three intervals are 1.91, 1.86, and 1.88 for $\mathrm{T} 1$ and $1.80,1.84$, and 1.80 at $\mathrm{T} 2$, suggesting that there is no change in the variability of scanning behaviour towards the end of the fixation sequence, as would be suggested by any holistic element of word processing.

While the landing position data clearly suggest a linear progression of word processing from left to right, they do not yet allow distinguishing between the type-writer vs. local clustering accounts. As outlined earlier, the identifying feature of the type-writer strategy would be a relatively small proportion of regressive intra word saccades and the existence of a distinct subpopulation of larger regressions that bring the eyes back to the word beginning.

To examine these possibilities, we determined saccade amplitudes and the proportions of intraword regressive and progressive saccades. FH's progressive saccades were characterized by extremely short amplitudes of 1.5 at T1 and 1.7 letters at T2, as opposed to approximately 5 letters in our control participants (see Table 5, $t$-test, Crawford \& Howell, T1: $p=.001 ; \mathrm{T} 2: p<.001)$. The difference in regressive saccades was less pronounced, with 2.0 letters at $\mathrm{T} 1$ and 1.5 letters at $\mathrm{T} 2$, in comparison 

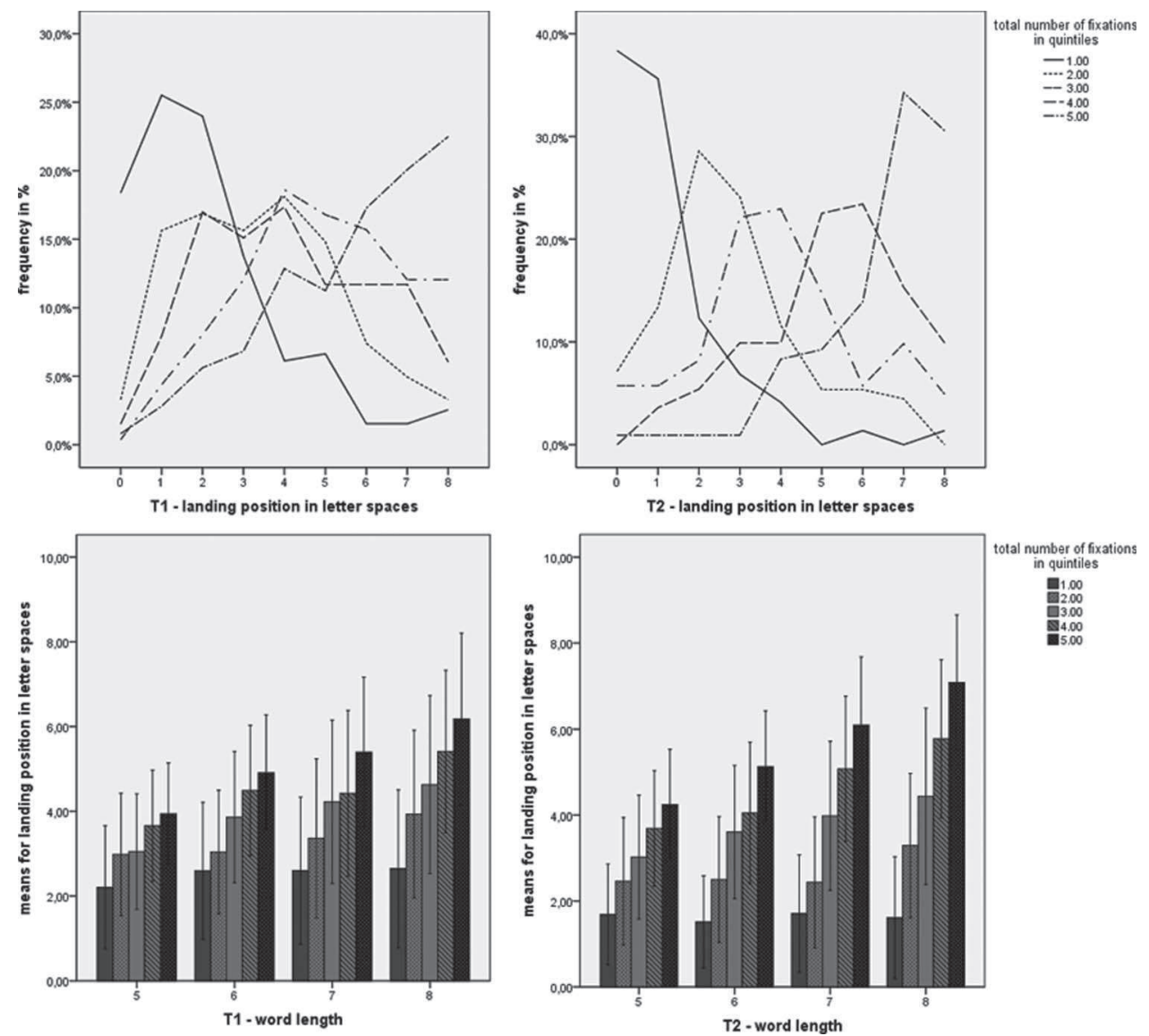

Figure 2. Upper panels: distributions of saccade landing positions at $\mathrm{T} 1$ and $\mathrm{T} 2$ for 8-letter words. Lower panels: mean landing positions at $\mathrm{T} 1$ and $\mathrm{T} 2$ for all word lengths.

to approximately 3 letters for controls (differences non-significant). Most characteristic for FH's oculomotor behaviour was the ratio between progressive and regressive saccades. At both testing point regressions accounted for more than a third of all saccades (T1: $38.4 \%$; T2: $34.8 \%$ ) as opposed to only $11 \%$ in the control group, which appears to point towards a local clustering strategy.

A final and critical step in our detailed analysis of regressive intraword saccades was to specify how often long regressions were used to bring the eye back to positions near the beginning of the word. To this end the percentage of intraword regressions was determined that traversed at least half the word length (counting the space before the word as letter position zero, see Figure 2), so that amplitudes of 3 letters and more were included for word length 5 and 6, and amplitudes of 4 and more for were included for word length 7 and 8. At T1, the percentage of such saccades (relative to all intraword saccades) was 3.5 for words length 5, 3.4 for word length 6, 2.7 for word length 7 and 3.2 for word length 8 . This already low proportion of longer range regressions dropped again quite dramatically at $\mathrm{T} 2$, with percentages 1.2 for word length $5,0.9$ for word length 6, 0.7 for word length 7 and 0.8 for word length 8 . To further illustrate these data, Figure 3 contrasts the combined frequency distributions of regressive intraword saccade amplitudes for word length 7 and 8 at T1 and T2. It appears clear from this figure that regressions of 4 letters and more are rare at $\mathrm{T} 1$ and almost disappear at $\mathrm{T} 2$, with no hint of any discontinuity in the distribution that might have suggested the existence type-writer like reverse movements.

\section{DISCUSSION}

The purpose of this study was to describe the recovery progression of $\mathrm{FH}$, a letter-by-letter reader, over a period of 15 months. FH suffered from 

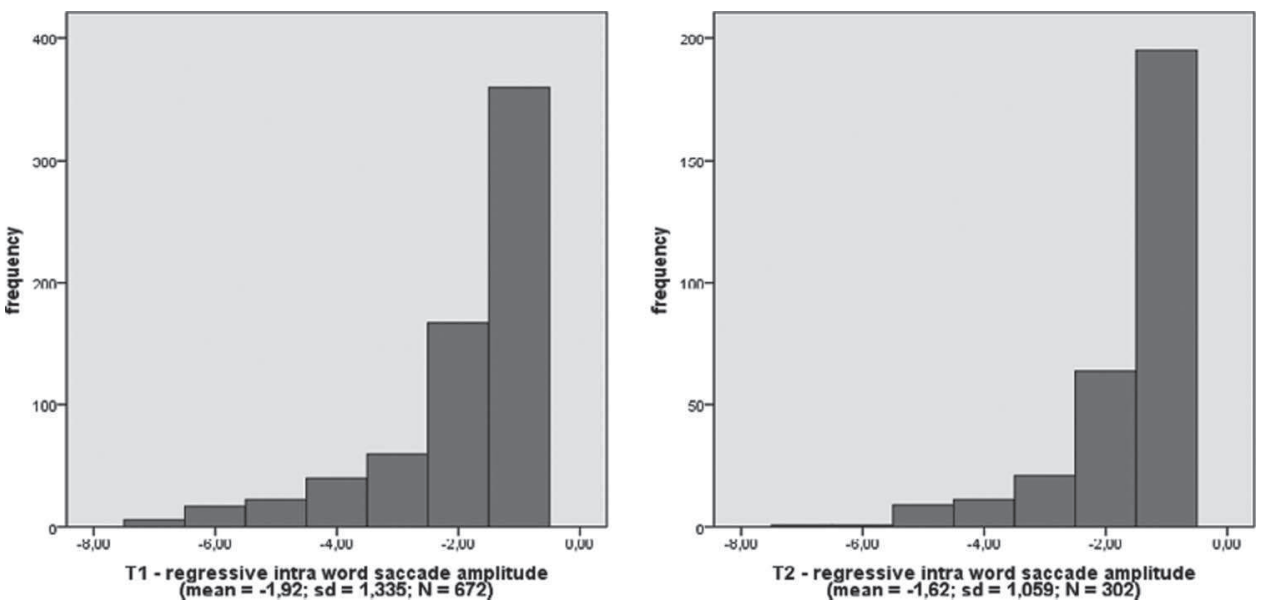

Figure 3. Combined frequency distributions of regressive intraword saccade amplitudes for 7- and 8-letter words at T1 and T2.

a temporal-occipital infarct which damaged the interconnections between the visual word form area (VWFA; Cohen et al., 2000, 2003) and the inferior parietal and posterior temporal language areas. In processing terms, the damage affected the direct matching of prelexical abstract letter representations to orthographic and phonological word form information. As a consequence, word recognition based on rapid parallel processing of letters guided by orthographic word activations was not possible. Instead, FH relied on effortful sounding out of letters. In chronic stage, he still presented a severe reading disorder, mainly characterized by an inflated total reading time and strongly influenced by word length. In contrast to classical cases of pure alexia (e.g., Arguin \& Bub, 1994; Patterson \& Kay, 1982), his graphic letter knowledge was not affected when there was no time limitation. In contrast to central surface dyslexia, he did neither show an inflated number of phonological errors nor regularizations of irregular orthography. His reading accuracy was high. From the perspective of clinical classification his reading impairment can be viewed as a variant of pure alexia, with the cardinal symptom of a pathological word length effect due to letter-by-letter reading.

So far, little is known about the long-term development of reading ability in patients with pure alexia (Behrmann et al., 1990; Friedman \& Alexander, 1984), especially with respect to their word processing strategies. We had the opportunity to examine $\mathrm{FH}$ at two testing points, 15 and 30 months post onset (T1, T2), combining eye movement analysis, speech recording and a battery of off-line tests. As an initial observation, FH's overt reading behaviour demonstrated a change from effortful letter-by-letter reading procedure at $\mathrm{T} 1$, to whole word responses after long latencies at $\mathrm{T} 2$, while our oculomotor data provided evidence for a very effortful, serial letter-by-letter strategy at T1 and still at T2. This interesting discrepancy indicated that detailed analysis of oculomotor data may provide insight that goes beyond the evidence provided by standard assessments of reading performance.

To characterize the recovery progress in detail, we used eye tracking methodology to detect minimal changes in temporal and spatial oculomotor measures related to reading on the word level. Although FH's reading process was characterized by very short progressive intraword saccade amplitudes at both testing points, he achieved gradual, but significant performance improvements. This was evident in the substantial reduction of total word viewing time and number of fixations per word, despite the persistence of a strong word length effect.

On a global level of analysis our results are quite consistent with Behrmann et al. (1990) who observed the reading behaviour of their patient DS over a period of 12 months, and Friedman and Alexander (1984), who followed the reading behaviour of another letter-by-letter reader over a period of 2 years. Although both prior studies emphasized improvements in response time, they also suggested that their patients had not achieved automaticity in their reading behaviour, which would explain the persistent word length effect. Even after applying specific therapeutic interventions, letter-by-letter readers do not seem to abandon their sequential reading strategy (Ablinger \& 
Domahs, 2009; Arguin \& Bub, 1994; Beeson, 1998; Behrmann \& McLeod, 1995; Bohn \& Stadie, 2005; Friedman \& Nitzberg Lott, 2000; Gonzalez Rothi \& Moss, 1992; Nitzberg Lott \& Friedman, 1999; Lott et Al., 1994; Sage et al., 2005). Instead, they appear to develop a more efficient adaptive strategy to compensate their reading difficulties.

This raises the question what letter-by-letter reading exactly looks like and which kind of changes, if any, occur in the reading process of such patients during the course of recovery. We considered a number of different scenarios of how letter-by-letter readers might approach word processing. The first of these scenarios, referred to as the type-writer strategy, assumed that reading would proceed in very small steps from left to right, literally processing letter-by-letter. This could be repeated several times by returning to the beginning of the word when the word was not initially recognized. The second possibility, labeled as a local clustering strategy, included a focus on the binding of small groups of letters. This strategy would make sense if evidence obtained from sublexical graphemic structure is gradually accumulated on the way to full lexical access. These variants of strongly serial processing were contrasted with the possibility that some degree of holistic word processing may also be involved. It appears reasonable to expect that during the course of recovery a return to more lexical word processing routines might be underway. Finally, we also considered the possibility of a lexical guessing strategy, characterized by visual guessing errors due to premature termination of word processing based on incomplete information.

This last alternative turned out to be easiest to exclude. FH did not apply a lexical guessing strategy to any noticeable degree, as his reading process never appeared abandoned prematurely and he hardly produced any lexical errors with visual similarity to the target word. Overall, FH made reading errors in $12.5 \%$ of all trials at $\mathrm{T} 1$, and in $6 \%$ at $\mathrm{T} 2$. Most errors were neologistic productions. Lexical errors with visual similarity to the target were very rare.

To distinguish between the remaining alternatives, a novel way to analyze the eye movement data of FH was developed. To this end, all fixations he made on a given target were partitioned into five equal portions to reflect the spatial and temporal dynamics of processing. This was combined with plotting the landing positions of the corresponding incoming saccades to obtain a description of the time line of where within words information was acquired. As one major result, we found that FH's peaks of fixation positions shifted from left to right in a linear fashion, indicating strictly serial processing on this level of temporal resolution. His last quintile of total number of fixations was almost exclusively positioned at the two endmost letters of a word. Therefore, elements of a 'holistic' processing strategy could not have been substantial, as in that case landing site distributions for the last quintile should have had a peak closer to the word center as is evidenced by the preferred viewing position of skilled readers (McConkie et al., 1988; Rayner, 1979).

A different angle of data analysis allowed looking into the sequential progression of word processing in still more detail. Across both testing points, FH maintained a very high proportion of regressive saccades so that one out of three saccades moved the eyes back to previously scanned positions within the same word. Most of these regressions had amplitudes of just one or two letters. Essentially he made his way slowly across the letters of each target word, frequently moving back and forth in a zigzag-like pattern. Looking at the distribution of regressive saccade amplitudes, it was evident that there was no distinct population of longer range regressions that would have moved the eyes back to positions near the word beginning. More generally, these data illustrate the status of regressions as part of a local routine of sublexical processing, as opposed to normal reading, where eye movements are primarily determined by word level processing (see Inhoff, Weger, \& Radach, 2005, for a detailed discussion of regressions in normal reading).

Taken together, our results provide solid support for the view that 'letter-by-letter reading' in FH took the form of a clustering strategy, with the observed hovering of the eyes over a given group of letters corresponding to attempts to form a local sublexical unit. While the visuomotor behaviour of FH was quite similar at both testing points, there was also substantial evidence for change from $\mathrm{T} 1$ to $\mathrm{T} 2$, both in terms of a more equidistant nature of fixation positions over time and the near disappearance of longer range regression. These subtle changes can be interpreted as a tendency for refinement towards a more homogenous scanning strategy as a basis of effective word processing. At the same time, FH's overt reading behaviour changed quite dramatically from sounding out letters at $\mathrm{T} 1$ to correct whole word productions with 
long latencies at $\mathrm{T} 2$, with the corresponding eye movement patterns verifying a similar (but gradually improving) sequential letter cluster processing strategy at both testing points.

There is no indication that FH's letter scanning strategy was mediated by hemianopic and/or oculomotor deficits. In a visually guided saccade task administered at $\mathrm{T} 1$ he did not exhibit any abnormalities with respect to saccade latency and leftward saccade amplitudes. Saccades to the right showed a mild impairment within amplitude range much larger than found in reading. Most importantly, his hemianopic field defect was mainly restricted to the right lower quadrant and did not affect the horizontal periphery up to 8 degrees (24 letters), completely sparing the much smaller region of central vision relevant for letter recognition and eye movement control in reading (see e.g., Rayner, 1998, for a detailed discussion).

As previously reported for letter-by-letter readers, FH also showed top-down effects, despite the preponderance of letter-by-letter type processing. These effects were demonstrated via both clinical and experimental examination. Even with relatively short stimulus presentation $(250 \mathrm{~ms}), \mathrm{FH}$ had almost no difficulties to recognize real words in a visual lexical decision task. Likewise, he was able to report the first and last letter of words and neologisms when they were short and briefly presented $(300 \mathrm{~ms})$. In contrast, reading aloud of similar words took him initially (T1) on the average almost 7 seconds and on retesting 15 months later (T2) still 4.4 seconds. Most strikingly, word frequency affected his total reading time and the total number of fixations at $\mathrm{T} 1$, but not at $\mathrm{T} 2$, while word semantics (concrete vs. abstract meaning) had a continuous, although decreasing, impact over the time course of 15 months.

Behrman, Plaut et al. (1998) discussed the appearance of lexicality and semantic effects in recovering letter-by-letter readers in terms of an interactive cascaded reading model (McClelland \& Rumelhart, 1981; Plaut, McClelland, Seidenberg, \& Patterson, 1996). In this framework, severe impairments in the fast and parallel processing of the orthographic input result in only partially degraded forward activation to subsequent processing levels, which in turn feed their activation back to lower levels. A straightforward assumption of such a model is that lexical access is faster for items with high than low frequency. A key reason for this difference may be that fragmentary letter information is in part compensated by top-down processes, which should be more efficient for high frequency words or concrete words in comparison to low frequency words or abstract words (Behrmann et al., 2001).

In an eye movement study Johnson and Rayner (2007) have recently demonstrated bottom-up and top-down influences in letter-by-letter reading based on a silent sentence reading experiment in which they varied word frequency and contextual constraint. In the present study oculomotor evidence for top-down processes emerged during reading aloud in the form of substantial semantic and word frequency effects. Both factors affected the number of fixations, consequently leading to substantial differences in total reading time. In addition to measures of viewing duration, we also looked at a critical spatial parameter, the distribution of saccade landing positions. These distributions showed very little change, in line with earlier evidence in normal readers suggesting very limited influence of cognitive factors on spatial aspects of eye movement control (e.g., Radach et al., 2004; Vainio, Hyönä, \& Pajunen, 2009).

An alternative view to compensatory top-down processes assumes that lexical frequency is already reflected in bottom-up processes and thereby affects FH's letter-by-letter reading. Several studies confirmed the involvement of the impact of lexical frequency in the very early processes of lexical access (Hauk, Davis, Ford, Pulvermüller, \& MarslenWilson, 2006; Knobel, Finkbeiner, \& Caramazza, 2008; Kronbichler et al., 2007; Proverbio \& Adorni, 2008; Proverbio, Zani, \& Adorni, 2008; White, 2008). The orthographic regularity of a particular letter string acts together with the strength of the corresponding lexical representation in memory to determine the cognitive workload that is measured in terms of fixation or gaze duration as a function of word frequency (see White, 2008, for a recent detailed discussion; Rayner \& Duffy, 1986). The early contribution of lexical frequency in word recognition was confirmed quite elegantly in recent ERP research (Hauk et al., 2006). These authors determined the time course of access to psycholinguistic information during visual word recognition. They found very early effects $(100 \mathrm{~ms})$ of word form related variables, such as word length and letter n-gram frequency, which were shortly followed $(110 \mathrm{~ms})$ by and partly overlapped with effects of lexical frequency. All these findings make it plausible to assume that lexical frequency already affected $\mathrm{FH}$ when he tried to decipher letter string information in reading aloud at T1. The lack of the frequency effect at $\mathrm{T} 2$ could be due to the reduced 
processing time. When orthographic segments are recognized more efficiently the impact of lexical frequency in letter string processing gets diminished.

A hallmark of FH's reading impairment is his inability to activate orthographic word forms directly, i.e., by combining abstract letter knowledge with incoming orthographic word form information. In fact, his impairment forces him to access phonological rather than orthographic word forms via sounding out letter strings. Initially sounding out was an overt process that accompanied his local clustering strategy, but during the course of recovery, the overt sounding out of words was replaced with correctly naming target word after exceedingly long latencies. Access to phonological word forms appears to be mostly unimpaired by FH's aphasic impairment as indicated by his outstandingly good repetition performance (transcortical-sensory aphasia). Therefore frequency had no or only little impact. In contrast, the concreteness effect remained substantial due to his aphasic impairment as reflected by lower performance in comprehension and confrontation naming.

Pathological letter-by-letter reading is assumed to be the result of damage to the VWFA (visual word form area) in the left mid fusiform gyrus and/or to adjacent connecting areas (Cohen et al., 2003; Damasio \& Damasio, 1983; Epelbaum et al., 2008). In FH, the lateral portion of VWFA as well as the adjacent temporal cortical and subcortical cortex were destroyed. Recently, several brain imaging studies have demonstrated for normal readers that the VWFA is not only engaged in letter string computation (Dehaene, LeClec'h, Poline, LeBiha, \& Cohen, 2002), but is strongly sensitive to orthographic stimulus properties (Bruno, Zumberge, Manis, Lu, \& Goldman, 2008; Cohen et al., 2000; Hauk et al., 2006; Kronbichler et al., 2007; Proverbio \& Adorni, 2008) and even to word frequency (Proverbio et al., 2008). The reading impairment of FH clearly demonstrates difficulties in fast and parallel letter string computation but abstract graphemic knowledge was available at least during the time of testing 15 months post onset. Most likely restitution of abstract graphemic letter processing occurred in the structural preserved part of the VWFA. Thus, letter recognition was accurate but remained slow.

Given the fact that cortical and subcortical areas adjacent to the VWFA were largely damaged, FH is another demonstration of a functional disconnection syndrome (Epelbaum et al., 2008; Geschwind, 1965; Stachowiak \& Poeck, 1976). Residual VWFA functions cannot be connected to inferior parietal functions which would enable orthographic whole word activation (Hillis et al., 2005). One could speculate how the functional and anatomical disconnection was circumvented when FH tried to activate wordforms by sounding out letters. In the literature of the 1980s the possibility of right hemisphere circumvention via intact callosal fibers was discussed (Geschwind, 1965; Stachowiak \& Poeck, 1976). Alternatively, intra left hemisphere transmission might have been enabled by residual fiber tracts connecting VWFA to the perisylvian language areas (Epelbaum et al., 2008).

In conclusion, the present study contributes to a better understanding of word processing mechanisms in recovering letter-by-letter readers. Novel ways to analyze eye movements enabled us to examine the temporal and spatial characteristics of visual processing during reading aloud at an unprecedented level of detail, providing a more fine-grained approach towards understanding the recovery process. In agreement with the findings of therapy outcome research (Ablinger \& Domahs, 2009; Arguin \& Bub, 1994; Beeson, 1998; Behrmann \& McLeod, 1995; Bohn \& Stadie, 2005; Friedman \& Nitzberg Lott, 2000; Gonzalez Rothi \& Moss, 1992; Nitzberg Lott \& Friedman, 1999; Lott et Al., 1994; Sage et al., 2005) and a few existing longitudinal studies (Behrmann et al., 1990; Friedman \& Alexander, 1984) we confirm that during recovery letter-byletter readers tend to maintain key elements of the reading strategies developed in response to their initial impairment.

Our more detailed analyses of FH's visuomotor behaviour indicated that such a strategy may not only be maintained but become more refined and automatized over the time course of recovery. Instead of slowly returning to a more normative type of word processing, he moved towards perfecting his effortful serial letter clustering strategy. This is certainly a positive step towards more reading efficiency, but it may also cement a generally non-optimal routine of processing. Future research including more patients similar to $\mathrm{FH}$ will be needed to determine whether the observed increase in efficiency at the cost of maintaining a pathological reading strategy constitutes the general norm in the recovery process of letter-by-letter readers.

Our data point to important implications for approaches to therapy. At present the techniques most frequently used with letter-by-letter readers are systematic single letter training on the one hand and whole word recognition approaches on the 
other (see Ablinger \& Domahs, 2009; Sage et al., 2005, for recent discussions). Assuming that the oculomotor pattern we described as local clustering reflects a focusing on the sequential recognition and synthesis of sublexical units, it appears quite promising to pursue a specific and systematic training of lexically informative letter clusters or even morphemes as an addition to the existing arsenal of therapeutic tools. As a consequence of this idea, it appears desirable to consider detailed oculomotor analyses of word reading strategies as a tool to guide decisions on the optimal therapy for individual cases of letter-by-letter reading.

Original manuscript received 22 December 2010 Revised manuscript accepted 22 December 2011 First published online 20 April 2012

\section{REFERENCES}

Ablinger, I., \& Domahs, F. (2009). Improved single-letter identification after whole-word training in pure alexia. Neuropsychological Rehabilitation, 19, 340-363.

Arguin, M., \& Bub, D. N. (1994). Pure alexia: Attempted rehabilitation and its implications for interpretation of the deficit. Brain and Language, 47, 233-268.

Arguin, M., \& Bub, D. (2005). Parallel processing blocked by letter similarity in letter-by-letter dyslexia: A replication. Cognitive Neuropsychology, 22, 589-602.

Arguin, M., Fiset, S., \& Bub, D. (2002). Sequential and parallel letter processing in letter-by-letter dyslexia. Cognitive Neuropsychology, 19, 535-555.

Beeson, P. M. (1998). Treatment for letter-by-letter reading: A case study. In A. L. Holland (Ed.), Approaches to the treatment of aphasia (pp. 153-177). Diego, CA: Singular Publishing Group.

Behrmann, M., Black, S. E., \& Bub, D. (1990). The evolution of pure alexia: A longitudinal study of recovery. Brain and Language, 39, 405-427.

Behrmann, M., \& McLeod, J. (1995). Rehabilitation for pure alexia: Efficacy of therapy and implications for models of normal word recognition. Neuropsychological Rehabilitation, 5, 149-180.

Behrmann, M., Nelson, J., \& Sekuler, E. B. (1998). Visual complexity in letter-by-letter reading: 'Pure' alexia is not pure. Neuropsychologia, 36, 1115-1132.

Behrmann, M., Plaut, D. C., \& Nelson, J. (1998). A literature review and new data supporting an interactive account of letter-by-letter reading. Cognitive Neuropsychology, 15, 7-51.

Behrmann, M., Shomstein, S. S., Black, S. E., \& Barton, J. J. (2001). The eye movements of pure alexic patients during reading and nonreading tasks. Neuropsychologia, 39, 983-1002.

Benson, D. F., Brown, J., \& Tomlinson, E. B. (1971) Varieties of alexia. Neurology 21,951-957.

Bohn, C., \& Stadie, N. (2005). Unterstützen perzeptuelle Schlüsselmerkmale die ganzheitliche Wortverarbeitung? Die Sprachheilarbeit, 50, 212-220.
Bruno, J. L., Zumberge, A., Manis, F. R., Lu, Z. L., \& Goldman, J. G. (2008). Sensitivity to orthographic familiarity in the occipito-temporal region. Neuroimage, 39, 1988-2001.

Cohen, L., Dehaene, S., Naccache, L., Lehéricy, S., Dehaene-Lambertz, G., Hénaff, \& M. A. (2000). The visual word form area: Spatial and temporal characterization of an initial stage of reading in normal subjects and posterior split-brain patients. Brain, 123, 291-307.

Cohen, L., Martinaud, O., Lemer, C., Lehericy, S., Samson, Y., Obadia, M., Slachevsky, A., \& Dehaene, S. (2003). Visual word recognition in the left and right hemispheres: Anatomical and functional correlates of peripheral alexias. Cerebral Cortex, 13, 1313-1333.

Crawford, J. R., \& Howell, D. C. (1998). Comparing an individual's test score against norms derived from small samples. The Clinical Neuropsychologist, 12, $482-486$.

Damasio, A. R., \& Damasio, H. (1983). The anatomic basis of pure alexia. Neurology, 33, 1573-1583.

De Bleser, R., Cholewa, J., Stadie, N., \& Tabatabaie, S. (2004). LeMo - Lexikon modellorientierte einzelfalldiagnostik bei aphasie, dyslexie und dysgraphie. München, Germany: Elsevier Deutschland.

Dehaene, S., LeClec'h, G., Poline, J. B., LeBiha, D., \& Cohen, L. (2002). The visual word form area: A prelexical representation of visual words in the fusiform gyrus. NeuroReport 13, 321-325.

De Renzi, E., Motti, F., \& Nichelli, P. (1980). Imitating gestures. A quantitative approach to ideomotor apraxia. Archives of Neurology, 37, 6-10.

Epelbaum, S., Pinel, P., Gaillard, R., Delmaire, C., Perrin, M., Dupont, S., Dehaene, S., \& Cohen, L. (2008). Pure alexia as a disconnection syndrome: New diffusion imaging evidence for an old concept. Cortex, 44, 962-974.

Farah, M. J., \& Wallace, M. (1991). Pure alexia as a visual impairment: A reconsideration. Cognitive Neuropsychology, 8, 313-334.

Fiset, D., Arguin, M., Bub, D., Humphreys, G. W., \& Riddoch, M. J. (2005). How to make the word-length effect disappear in letter-by-letter dyslexia: Implications for an account of the disorder. Psychological Science, 16, 535-541.

Fiset, D., Arguin, M., \& McCabe, E. (2006). The breakdown of parallel letter processing in letterby-letter dyslexia. Cognitive Neuropsychology, 23, 240-260.

Friedman, R. B., \& Alexander, M. P. (1984). Pictures, images and pure alexia: A case study. Cognitive Neuropsychology, 1, 9-23.

Friedman, R. B., \& Nitzberg Lott, S. (2000). Rapid word identification in pure alexia is lexical but not semantic. Brain and Language, 72, 219-237.

Geschwind, N. (1965). Disconnexion syndromes in animals and man. Brain, 88, 237-943.

Gonzalez Rothi, L. J., \& Moss, S. (1992). Alexia without agraphia: Potential for model assisted therapy. Clinical Communication Disorders, 2, 11-18.

Greenwald, M. L., \& Gonzalez Rothi, L. J. (1998). Lexical access via letter naming in a profoundly alexic and anomic patient: A treatment study. Journal of the Internal Neuropsychological Society, 4, 595-607. 
Hanley, J. R., \& Kay, J. (1996). Reading speed in pure alexia. Neuropsychologia, 34, 1165-1174.

Hauk, O., Davis, M. H., Ford, M., Pulvermüller, F., \& Marslen-Wilson, W. D. (2006). The time course of visual word recognition as revealed by linear regression analysis of ERP data. Neuroimage, 30, $1383-1400$.

Hillis, A. E., Newhart, M., Heidler, J., Barker, P., Herskovits, E., \& Degaonkar, M. (2005). The roles of the 'visual word form area' in reading. Neuroimage, 24, 548-559.

Huber, W., Klingenberg, G., Poeck, K., \& Willmes, K. (1993). Die supplemente zum aachener aphasie und resultate der validierung. Neurolinguistik, 7, 43-66.

Huber, W., Poeck, K., Weniger, D., \& Willmes, K. (1983). Der Aachener Aphasie Test (AAT). Göttingen, Germany: Hogrefe.

Huber, W., Poeck, K., \& Willmes, K. (1985). The Aachen aphasia test. In F. C. Rose (Ed.), Progress in aphasiology (pp. 291-303). New York, NY: Raven.

Hund, M., \& Huber, W. (1991). Eye movement behavior of brain damaged patients with cerebral microand macroangiopathy in simple visual detection tasks. Brain, 114, 1315-1321.

Horn, W. (1983). Leistungsprüfsystem (LPS). Handanweisung. Göttingen, Germany: Hogrefe.

Inhoff, A. W., \& Radach, R. (1998). Definition and computation of oculomotor measures in the study of cognitive processes. In G. Underwood (Ed.). Eye guidance in reading and scene perception (pp. 29-53). Oxford, UK: Elsevier.

Inhoff, A. W., Weger, U. W., \& Radach, R. (2005). Sources of information for the programming of shortand long-range regressions during reading. In G. Underwood (Ed.) Cognitive processes in eye guidance (pp. 33-52). Oxford, UK: Oxford University Press.

Johnson, R. L., \& Rayner, K. (2007). Top-down and bottom-up effects in pure alexia: Evidence from eye movements. Neuropsychologia, 45, 2246-2257.

Kay, J., Lesser, R., \& Coltheart, M. (1992). Psycholinguistic assessments of language processing in aphasia (PALPA). Hove, UK: Erlbaum.

Knobel, M., Finkbeiner, M., \& Caramazza, A. (2008). The many places of frequency: Evidence for a novel locus of the lexical frequency effect in word production. Cognitive Neuropsychology, 25, 256-286.

Kronbichler, M., Bergmann, J., Hutzler, F., Staffen, W. Mair, A., Ladurner, G., \& Wimmer, H. (2007). Taxi vs. Taksi: On orthographic word recognition in the left ventral occipitotemporal cortex. Journal of Cognitive Neuroscience, 19, 1584-1594.

Leff, A. P., Scott, S. K., Crewes, H., Hodgson, T. L., Cowey, A., Howard, D., et al. (2000). Impaired reading in patients with right hemianopia. Annals of Neurology, 47, 171-178.

Lambon Ralph, M. A., Hesketh, A., \& Sage, K. (2004). Implicit recognition in pure alexia: The safran effect - a tale of two systems or two procedures? Cognitive Neuropsychology, 21, 401-421.

Lott, S. N., Friedman, R. B., \& Linebaugh, C. W. (1994). Rationale and efficacy of a tactile-kinaesthetic treatment for Alexia. Aphasiology, 8, 181-195.
McClelland, J. L., \& Rumelhart, D. E. (1981). An interactive activation model of context effects in letter perception: Part 1. An account of basic findings. Psychological Review, 88, 375-407.

McConkie, G. W., Kerr, P. W., Reddix, M. D., \& Zola, D. (1988). Eye movement control during reading: I. The location of initial eye fixation on words. Vision Research, 28, 1107-1118.

McDonald, A. A., Spitsyna, G., Shillcock, R. C., Wise, R. J., \& Leff, A. P. (2006). Patients with hemianopic alexia adopt an inefficient eye movement strategy when reading text. Brain, 129, 158-167.

Mycroft, R. H., Behrman, M., \& Kay, J. (2009). Visuoperceptual deficits in letter-by-letter reading? Neuropsychologia , 47, 1733-1744.

Nitzberg, L. S., \& Friedman, R. B. (1999). Can treatment for pure alexia improve letter-by-letter reading speed without sacrificing accuracy? Brain and Language, 67, 188-201.

Oldfield, R. C. (1971). The assessment and analysis of handedness: The Edingburgh inventory. Neuropsychologia, 9, 97-110.

Patterson, K., \& Kay, J. (1982). Letter-by-letter reading: Psychological descriptions of a neurological syndrome. Quarterly Journal of Experimental Psychology, A, 34, 411-441.

Pflugshaupt, T., Gutbrod, K., Wurtz, P., von Wartburg, R., Nyffeler, T., de Haan, B., et al. (2009). About the role of visual field defects in pure alexia. Brain, 132, 1907-1917.

Pflugshaupt, T., Suchan, J, Mandler, M.-A., Sokolov, A., Trauzettel-Klosinski, S., \& Karnath, H.-O. (2011). Do patients with pure alexia suffer from a specific word form processing deficit? Evidence from 'wrods with trasnpsoed letetrs'. Neuropsychologia, 49, 1294-1301.

Plaut, D. C., McClelland, J. L., Seidenberg, M. S., \& Patterson, K. (1996). Understanding normal and impaired word reading: Computational principles in quasi-regular domains. Psychological Review, 103, $56-115$.

Poeck, K. (1997). Motorische apraxie. In W. Hartje \& K. Poeck (Eds.), Klinische neuropsychologie. Stuttgart, Germany: Thieme.

Proverbio, A. M., \& Adorni, R. (2008). Orthographic familarity, phonological legality and number of orthographic neighbours affect the onset of ERP lexical effects. Behavioral and Brain Functions, 4, 1-13.

Proverbio, A. M., Zani, A., \& Adorni, R. (2008). The left fusiform area is affected by written frequency of words. Neuropsychologia, 45, 2292-2299.

Radach, R., Inhoff, A. W., \& Heller, D. (2004). Orthographic regularity gradually modulates saccade amplitudes in reading. European Journal of Cognitive Psychology, 16, 27-51.

Radach, R., \& Kennedy, A. (2004). Theoretical perspectives on eye movements in reading: Past controversies, current issues, and an agenda for future research. European Journal of Cognitive Psychology, 16, 3-26.

Rayner, K. (1979). Eye guidance in reading: Fixation locations within words. Perception, 8, 21-30.

Rayner, K. (1998). Eye movements in reading and information processing: 20 years of research. Psychological Bulletin, 124, 372-422. 
Rayner, K., \& Duffy, S. A. (1986). Lexical complexity and fixation times in reading: Effects of word frequency, verb complexity, and lexical ambiguity. Memory \& Cognition, 14, 191-201.

Rayner, K., \& Johnson, R. L. (2005). Letter-by-letter acquired dyslexia is due to the serial encoding of letters. Psychological Science, 16, 530-534.

Rayner, K., Well, A. D., Pollatsek, A., \& Bertera, J. H. (1982). The availability of useful information to the right of fixation in reading. Perception \& Psychophysics, 31, 537-555.

Roberts, D. J., Lambon Ralph, M. A., \& Woollams, A. M. (2010). When does less yield more? The impact of severity upon implicit pure alexia. Neuropsychologia, 48, 2437-2446.

Riddoch, M. J., \& Humphreys, G. W. (1993). Birmingham Object Recognition Battery. Hove, UK: Lawrence Erlbaum Associates Ltd.

Rosazza, C., Appolloniom I., Isella, V., \& Shallice, T. (2007). Qualitatively different forms of pure alexia. Cognitive Neuropsychology, 24, 393-418.

Saffran, E. M., \& Coslett, H. B. (1998). Implicit vs. letterby-letter reading in pure alexia: A tale of two systems. Cognitive Neuropsychology, 15, 141-165.

Sage, K., Hesketh, A., \& Ralph Lambon, M. A. (2005). Using errorless learning to treat letterby-letter reading: Contrasting word versus letterbased therapy. Neuropsychological Rehabilitation, 15, 619-642.

Schattka, K. I., Radach, R., \& Huber, W. (2010). Eye movement correlates of acquired central dyslexia. Neuropsychologia, 48, 2959-2973.

Schuett, S., Kentridge, R. W., Zihl, J., \& Heywood, C. A. (2009). Are hemianopic reading and visual exploration impairments visually elicited? New insights from eye movements in simulated hemianopia. Neuropsychologia, 49, 733-746.
Seki, K., Yajima, M., \& Sugishita, M. (1995). The efficacy of kinesthetic reading treatment for pure alexia. Neuropsychologia, 33, 595-609.

Shallice, T., \& Saffran, E. M. (1986). Lexical processing in the absence of explicit word identification: Evidence from a letter-by-letter reader. Cognitive Neuropsychology, 3, 429-458.

Smirni, P., Villadita, C., \& Zappala, G. (1983). Influence of different paths on spatial memory performance in the Block-Tapping Test. Journal of Clinical Neuropsychology, 111, 67-71.

Stachowiak, F. L., \& Poeck, K. (1976). Functional disconnection in pure alexia and color naming deficit demonstrated by facilitation methods. Brain and Language, 3, 135-143.

Starrfelt, R., Habekost, T., \& Leff, A. P. (2009). Too little, too late: Reduced visual span and speed characterize pure alexia. Cerebral Cortex, 19, 2880-2890.

Sturm, W., \& Willmes, K. (1999). Nonverbaler Lerntest (NVLT). Göttingen: Hogrefe.

White, S. J. (2008). Eye movement control during reading: Effects of word frequency and orthographic familarity. Journal of Experimental Psychology, 34, 205-223.

Underwood, N. R., \& McConkie, G. W. (1985). Perceptual span for letter distinctions during reading. Reading Research Quarterly, 20, 153-162.

Vainio S., Hyönä, J., \& Pajunen, A. (2009). Lexical predictability exerts robust effects on fixation duration, but not on initial landing position during reading. Experimental Psychology, 56, 66-74.

Zihl, J. (1995a). Visual scanning behavior in patients with homonymous hemianopia. Neuropsychologia, 33, 287-303.

Zihl, J. (1995b). Eye movement patterns in hemianopic dyslexia. Brain, 118, 891-912.

Zimmermann, P., \& Fimm, B. (1997). TAP Test for attentional performance. Herzogenrath, Germany: Psytest. 